\title{
Respiratory Airway Resistance Monitoring In Mechanically Ventilated Patients
}

\author{
Nor Salwa Damanhuri, Yeong Shiong Chiew, \\ Paul D. Docherty, Patrick H. Geoghegan, J. Geoffrey Chase
}

Centre for Bioengineering, University of Canterbury Christchurch, New Zealand 


\section{INTRODUCTION}

Damaged lung due to over inflation

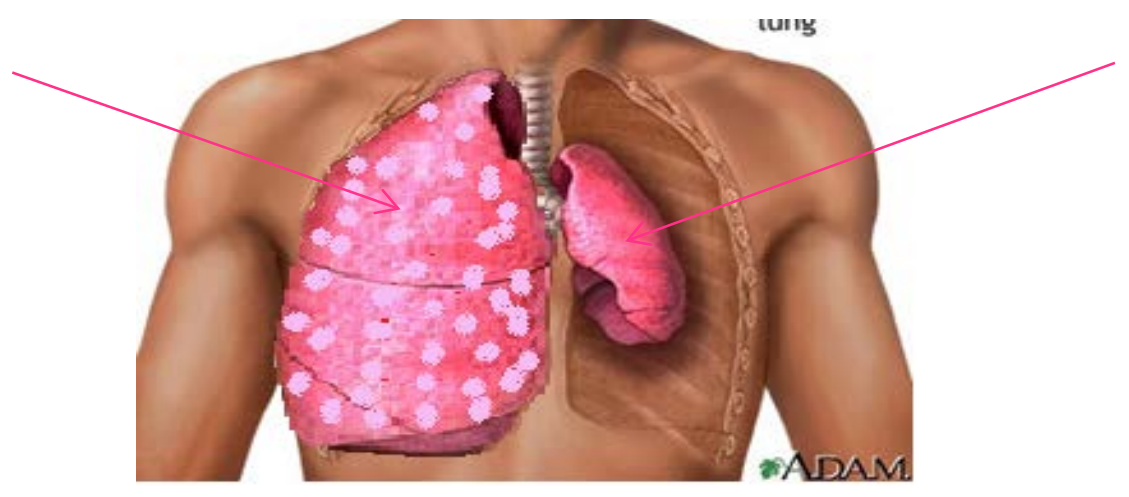

Collapsed lung

- Modelling respiratory mechanics enables patient-specific understanding of lung physiology for optimal Mechanical Ventilation (MV) of critically ill patients

- However, only few models have been designed with a specific therapeutic goal or outcome

- Higher pressure provided by MV allow increased recruitment but can also cause over-distension to the alveoli - ventilator induced lung injury (VILI)

Thus, the motivation of this research is to determine the pressure drop for each branch of the airway system by estimating the airway resistance, which can be used as a clinical guidelines to prevent the alveoli from over-distension 


\section{Airway Models}

- What is Pressure drop? Why it is important?

- The pressure drop is due to the resistive components in the airway branching system.

- It is important as it can estimate the end alveoli pressure that could cause lung injury due to the over-distension

- 3 airway models are used in estimating the pressure drop due to airway resistance in MV patients with ARDS

1. Airway Branching Model (ABM)

2. Single Compartment Linear Lung Model (LLM)

3. The Dynostatic Model (DSM) 


\section{ABM Model}

- The pressure drop at each airway branch is estimated by Poiseulle equation:

$$
\Delta P_{n}=R_{n} Q_{n}
$$

- The respiratory airways are branched into generations starting from trachea (Generation 0) through to the alveoli (Generation 23)

- In this model, $Q_{n}$ is the flow rate of each airway branch. Thus, flow rate at each branch is assumed to be half of the previous generation flow rate:

$$
Q_{n+1}=\frac{1}{2} Q_{n}
$$

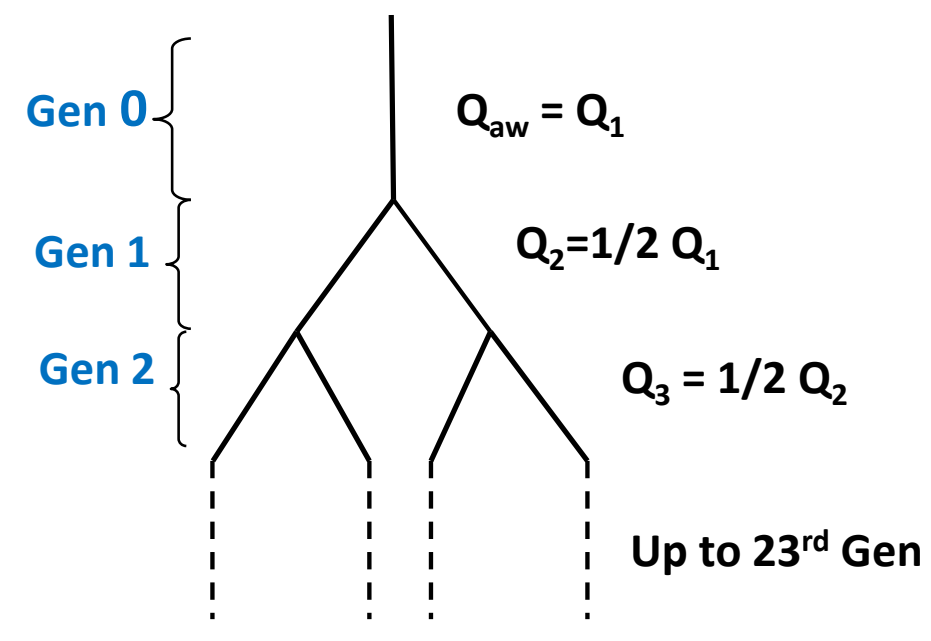




\section{ABM Model}

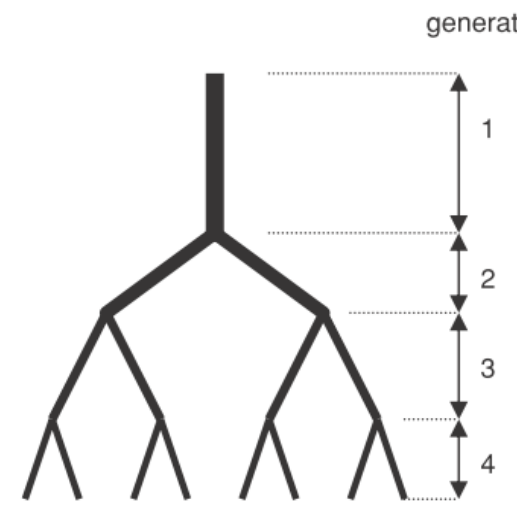

- Bates (2009)

\begin{tabular}{|c|c|c|}
\hline Branch Generations & Diameter $(\mathbf{c m})$ & Length (cm) \\
\hline $\mathbf{0}$ (Tracheal) & 1.80 & 12.0 \\
\hline $\mathbf{1}$ & 1.22 & 4.80 \\
\hline $\mathbf{2}$ & 0.83 & 1.90 \\
\hline $\mathbf{3}$ & 0.56 & 0.80 \\
\hline $\mathbf{4}$ & 0.45 & 1.30 \\
\hline $\mathbf{5}-\mathbf{1 6}$ & $0.35-0.06$ & $1.07-0.17$ \\
\hline $\mathbf{1 7}-\mathbf{2 2}$ & 0.05 & 0.10 \\
\hline $\mathbf{2 3}$ & 0.04 & 0.05 \\
\hline
\end{tabular}

- Based on measured airway dimensions measured by Pedley et al.

- The airway resistance is estimated by using Poiseulle flow:

$$
R_{n}=\frac{1}{2^{n}}\left(\frac{128 \mu L}{\pi d^{4}}\right)
$$

$\bullet \mu$ - dynamic viscosity of air (Pa.s)

•n- airway branch generation

$\cdot L$ - length of airway branch $(\mathrm{m})$

$\cdot d$ - diameter of airway branch $(\mathrm{m})$

- Thus, the total pressure drop of the ABM model can be modelled:

$$
\Delta P_{R_{-} A B M}=\sum_{n=0}^{23} R_{n} Q_{n}
$$

1. J. H. T. Bates, Lung mechanics an inverse modelling approach vol. 1. United States of America: Cambridge University Press, 2009 


\section{LLM Model}

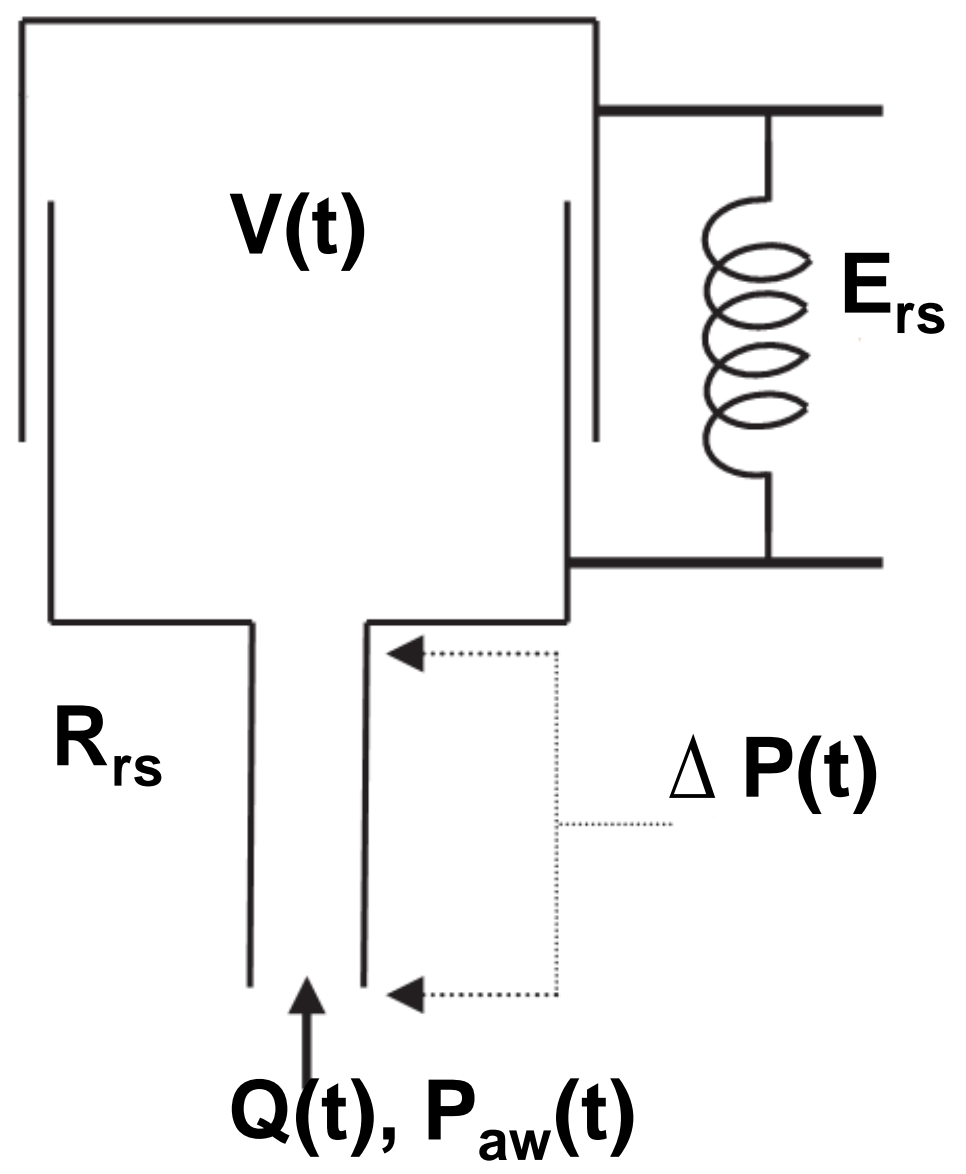

- This model is based on equation of motion:

$$
\begin{aligned}
& P_{a w}=E_{r s} V+R_{r s} Q_{a w}+P_{0} \\
& \cdot \mathrm{P}_{\mathrm{aw}}-\text { airway pressure } \\
& \cdot \mathrm{E}_{\mathrm{rs}} \mathrm{V} \text { - alveoli pressure } \\
& \cdot \mathrm{R}_{\mathrm{rs}} \mathrm{Q}_{\mathrm{aw}} \text { - resistive pressure } \\
& \cdot \mathrm{P}_{0}-\text { offset pressure }
\end{aligned}
$$

- By using integral-based methods, the resistive pressure drop can be estimated:

$$
\Delta P_{R_{-} L L M}=R_{r s} Q_{a w}
$$


- The dynostatic algorithm is used to estimates the dynostatic pressure, $P_{d y n}$, which could be used as a "gold standard" in estimating the alveolar pressure.

- The inspiration airway resistance, $R_{\text {insp }}$ is assumed to be the same as the expiration airway resistance, $R_{\text {exp }}$ at iso-volume:

$$
\begin{gathered}
R_{\text {exp }}=\frac{P_{\text {exp }}-P_{d y n}}{\dot{V}_{\text {exp }}} \\
R_{\text {insp }}=\frac{P_{i n s p}-P_{d y n}}{\dot{V}_{\text {insp }}} \\
\text { At iso-volume, } V_{\text {iso }} \\
R_{\text {insp }}=R_{\exp }
\end{gathered}
$$


- Thus, the $P_{d y n}$ is calculated as below:

$$
P_{d y n}=\frac{P_{i n s p} \times \dot{V}_{\exp }-P_{\exp } \times \dot{V}_{i n s p}}{\dot{V}_{\text {exp }}-\dot{V}_{i n s p}}
$$

- Finally, the resistive pressure during inspiration is modelled as:

$$
\Delta P_{R_{-} D y n}=\dot{V}_{i n s p} R_{i n s p}=P_{i n s p}-P_{d y n}
$$




\section{Data Analyses}

- The 3 airway models are used to determine the resistive pressure or pressure drop from the airway to the alveoli in 6 ARDS patients from 2 different cohorts with PEEP of $5 \mathrm{cmH}_{2} \mathrm{O}$.

- 3 patients (B1-3) have constant square wave input profiles while the other 3 patients (S1-3) are ventilated using a decreasing input flow profile.

- Each model is simulated using measured $P_{a w}$ and $Q_{a w}$ and flow rate at the airway. 


\section{Results and Discussion}

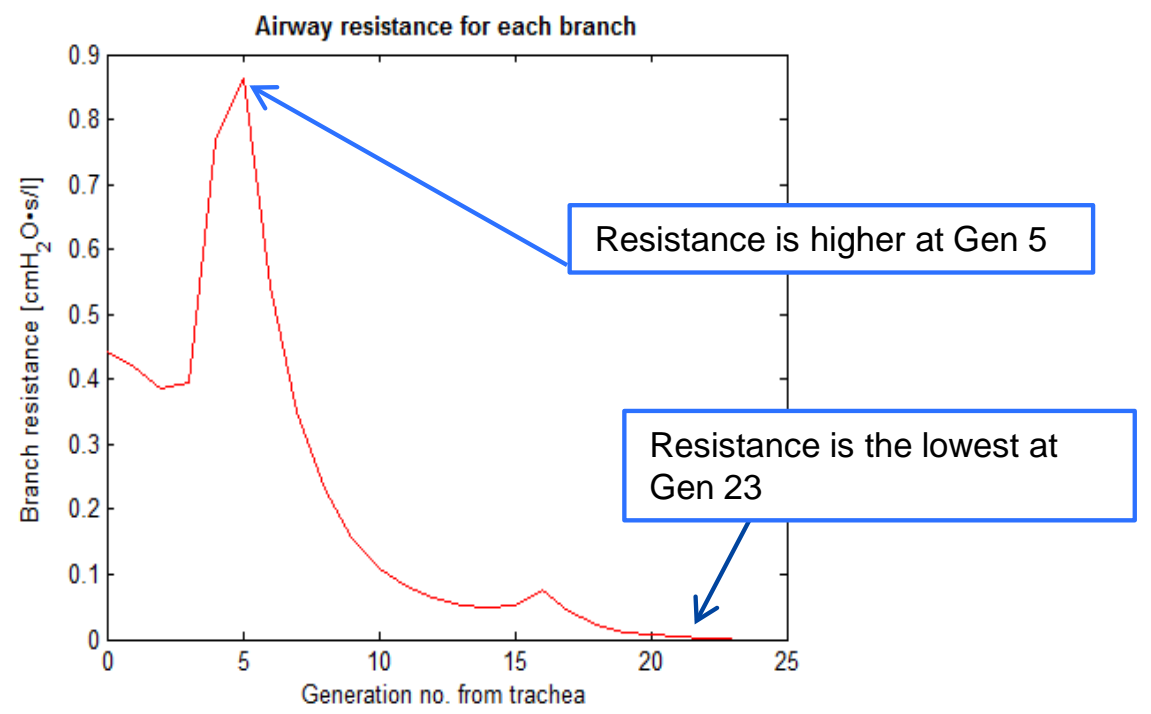

- From the ABM model, the estimated resistance at each branch starting from Gen 0 to Gen 23.

- Resistance higher at the $5^{\text {th }}$ generation branch due to the higher length at this branch. The total resistance for all branches

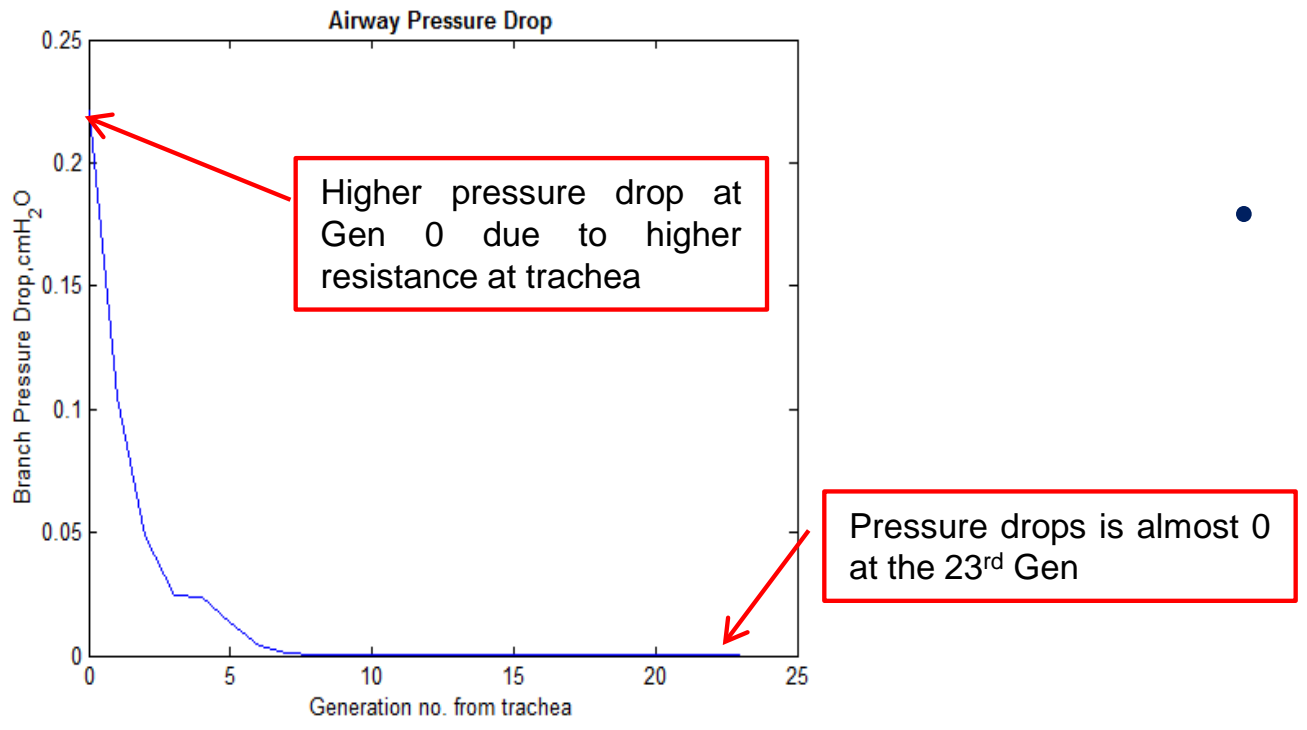
is $5.13 \mathrm{cmH}_{2} 0 . \mathrm{s} / 1$.

- The estimated pressure drop at each branch with highest pressure drop at Gen 0 (trachea) at 0.23 $\mathrm{CmH}_{2} \mathrm{O}$. 


\section{Results and Discussion}
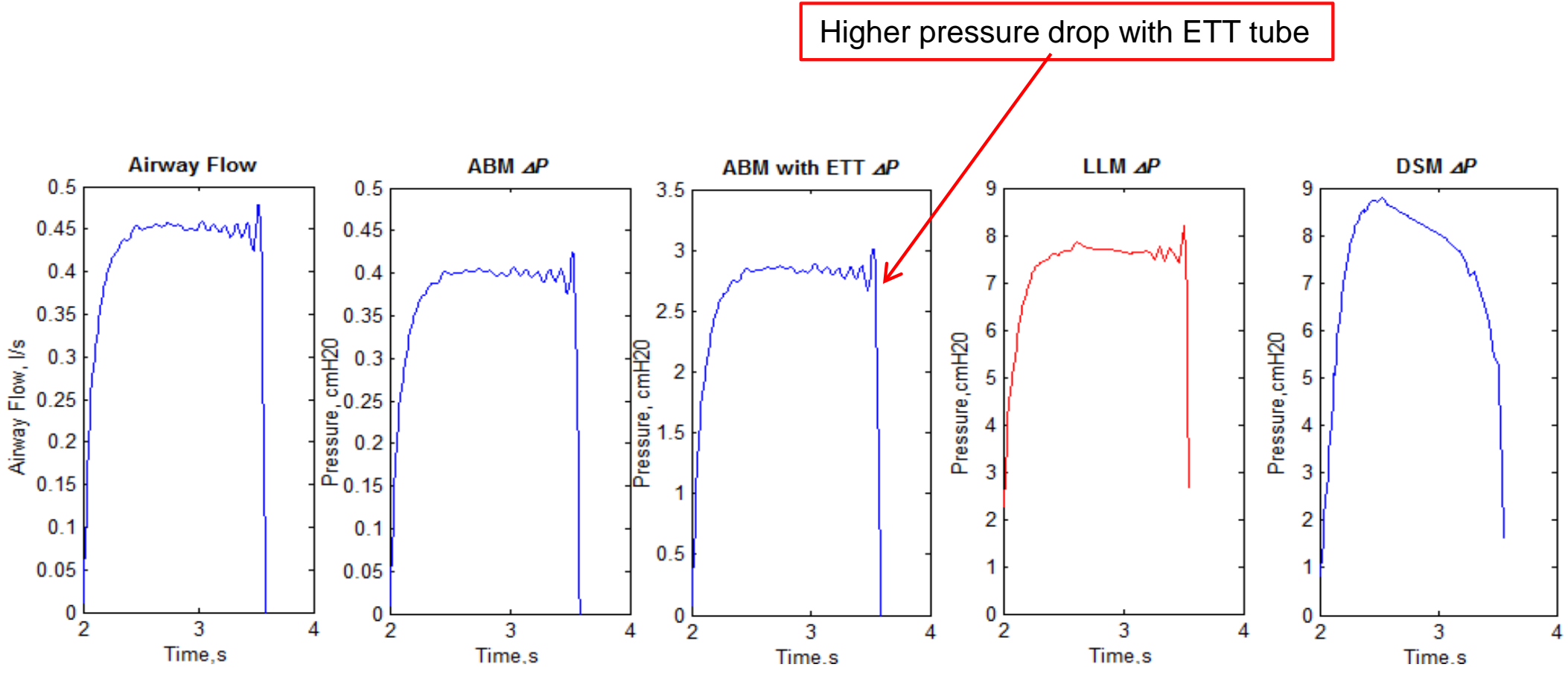

- The comparison of pressure drop for the three models.

- The maximum pressure drop for LLM and DSM models ranges from 8.2 to 8.8 $\mathrm{CmH}_{2} \mathrm{O}$.

- For ABM model, the maximum pressure drop is $0.43 \mathrm{cmH}_{2} \mathrm{O}$ and increases to $3.0 \mathrm{cmH}_{2} \mathrm{O}$ with ETT tube. 


\section{Results and Discussion}
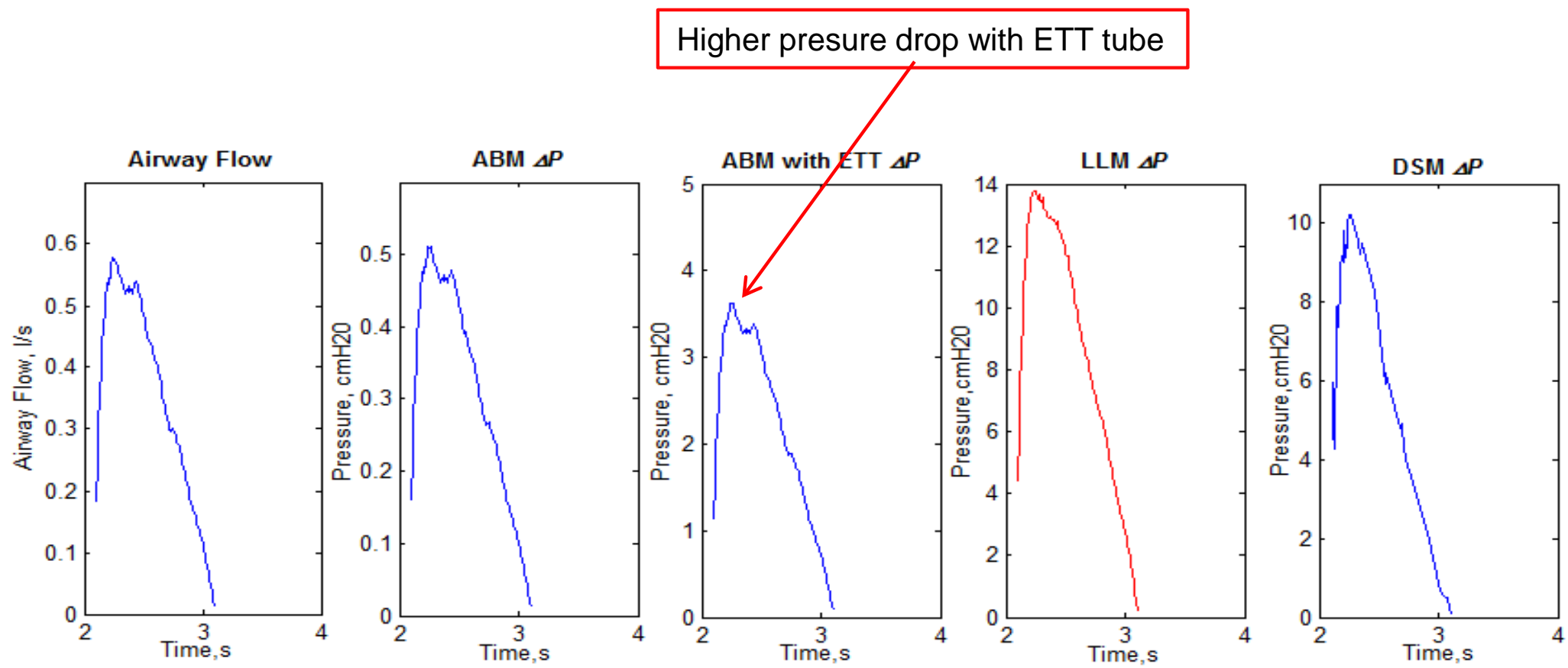

- The comparison of pressure drop for the three models.

- Patient $\mathrm{S1}$ is ventilated at higher flow rate $(0.61 / \mathrm{s})$, resulting in higher pressure drop.

- For ABM model, the maximum pressure drop is $0.51 \mathrm{cmH}_{2} \mathrm{O}$ and increases to $3.6 \mathrm{cmH}_{2} \mathrm{O}$ with ETT tube.

- For LLM and DSM model, the maximum pressure drop ranges from 10.2 to $13.8 \mathrm{cmH}_{2} \mathrm{O}$. 


\section{Results and Discussion}

- The median [IQR] and maximum value of the pressure drop for the three models are:

\begin{tabular}{|c|c|c|c|c|c|}
\hline \multicolumn{2}{|c|}{ ABM with ETT } & \multicolumn{2}{c|}{ LLM } & \multicolumn{2}{c|}{ DSM } \\
\hline $\begin{array}{c}\text { Median } \\
\text { [IQR] }\end{array}$ & Max & $\begin{array}{c}\text { Median } \\
{[\text { [QR }]}\end{array}$ & Max & $\begin{array}{c}\text { Median } \\
\text { [lQR] }\end{array}$ & Max \\
\hline 2.1 & 3.6 & 9.1 & 17.8 & $\begin{array}{l}4.0 \\
{[1.7-7.9]}\end{array}$ & 10.2 \\
{$[1.4-3.3]$} & & {$[5.3-12.6]$} & & & \\
\hline
\end{tabular}

- The pressure drop in LLM and DSM models are higher than the ABM model as expected.

- because the LLM and DSM are consists of lumped bronchial airway resistance where as for $A B M$, the pressure drop are based on physiological information at every branch of the bronchial generations.

- The ABM model allows pressure drops at every branch generation to be estimated as alveoli begin to appear at branch 17.

- Thus, this study allows insight into the pressure flow mechanics of alveoli recruitment that is not possible with lumped parameter models. 


\section{Conclusion and Future Work}

- By estimating the pressure drop due to resistive component is important to estimate the end alveoli pressure that could be used in clinical guidance in order to avoid further lung injury and reduce treatment cost.

- Model improvement and modification

- To use a range of airway dimensions for each specific patients, which will result in different pressure values.

- To consider the head losses due to the bifurcation at each of the branching bronchial

- The losses that occurs in the airway branching system due to the bifurcations in the respiratory tract is known as the minor head loss or pressure loss.

- because every time it change to the next branch, there is a change in the velocity distribution 


\section{Future Work}

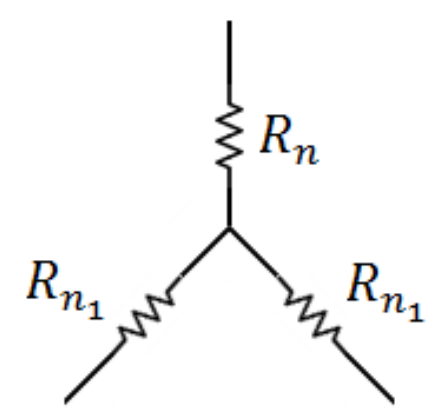

Current ABM model

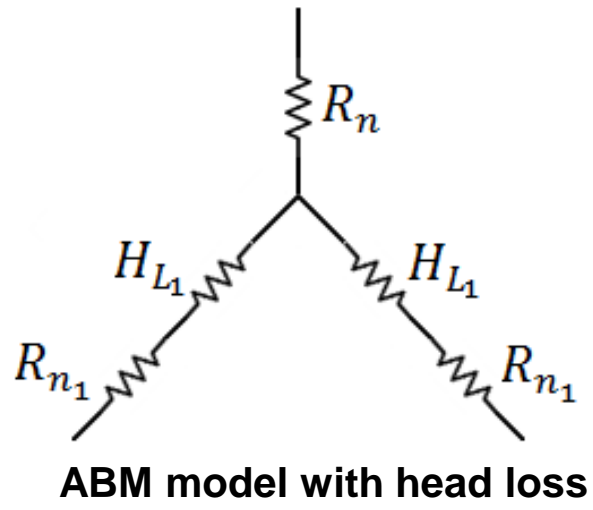

The minor head loss equation is :

$$
H_{L}=K_{L} \frac{V^{2}}{2 g}
$$

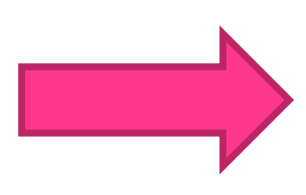

- $K_{L}-$ minor loss coefficient

- $V$ - velocity $(\mathrm{m} / \mathrm{s})$

-g-gravity $\left(\mathrm{m} / \mathrm{s}^{2}\right)$

Thus, the total pressure drop is :

$$
\Delta P_{T}=\sum_{n=0}^{23}\left(R_{n}+H_{L n}\right) Q_{n}
$$

$$
\cdot H_{L O}=0
$$




\section{Future Work}

- For example, for patient B1 at the same PEEP $5 \mathrm{cmH}_{2} 0$, the pressure drop with head loss is higher compared to the ABM model

\begin{tabular}{|l|c|c|l|l|}
\hline \multicolumn{1}{|c|}{ Patient } & \multicolumn{2}{c|}{ ABM with head loss } & \multicolumn{2}{c|}{ ABM } \\
\hline \multirow{2}{*}{ M1 } & Median [IQR] & Max & \multicolumn{1}{c|}{ Median [IQR] } & Max \\
\hline $\begin{array}{c}5.02 \\
{[4.53-5.19]}\end{array}$ & 5.69 & $\begin{array}{l}2.1 \\
{[2.2-2.2]}\end{array}$ & 2.3 \\
\hline
\end{tabular}




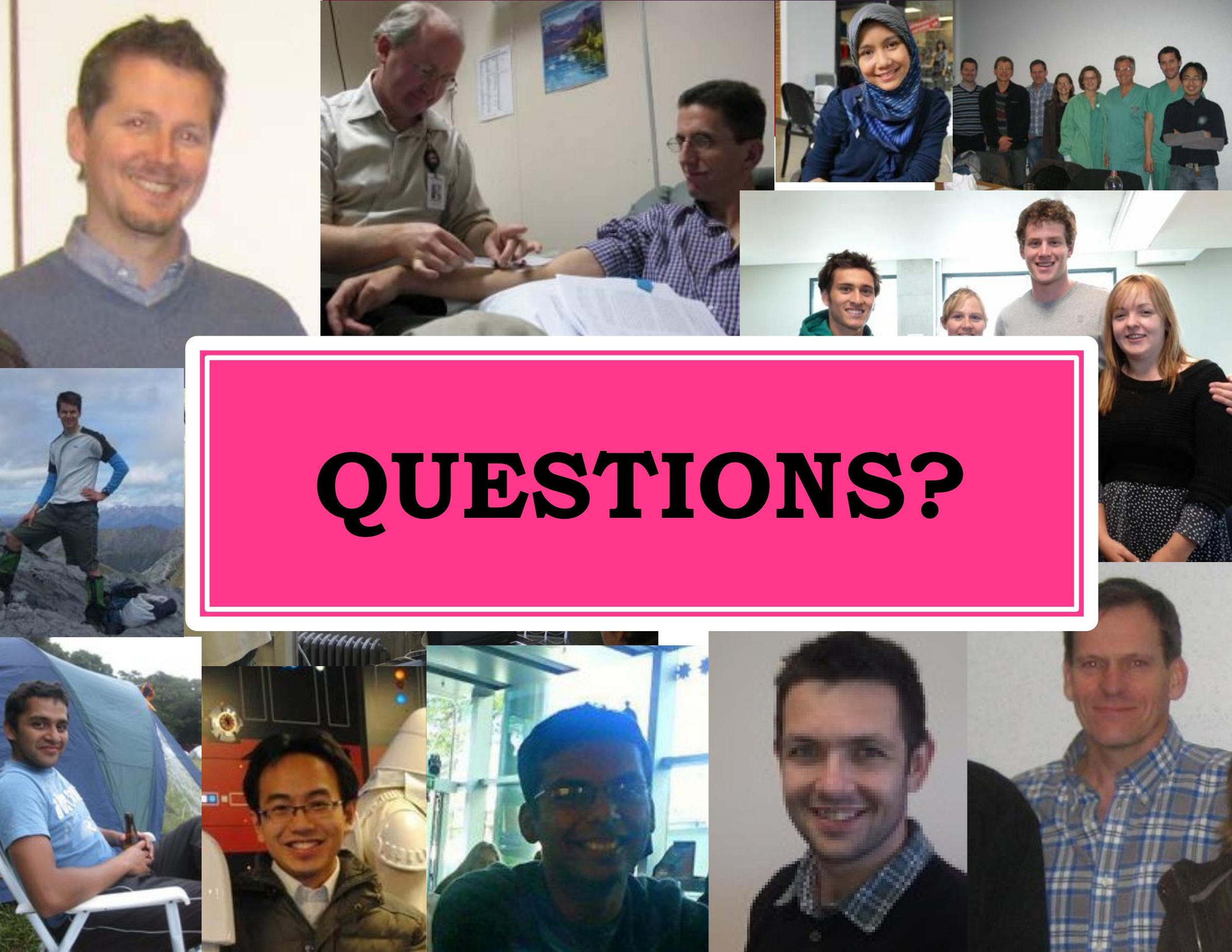

